\title{
Impact of pharmacist-led home medicines review services on drug-related problems among the elderly population: a systematic review
}

\author{
Sai Krishna Gudi ${ }^{1}$ Ananth Kashyap², Manik Chhabra ${ }^{3}$, Muhammed Rashid ${ }^{4}$, Komal Krishna Tiwari ${ }^{5}$ \\ ${ }^{1}$ Rady Faculty of Health Sciences, University of Manitoba College of Pharmacy, Winnipeg, Canada; ${ }^{2}$ Department of Pharmacy Practice, Sarada \\ Vilas College of Pharmacy, Mysuru, India; ${ }^{3}$ Department of Pharmacy Practice, Indo-Soviet Friendship College of Pharmacy, Moga, India; \\ ${ }^{4}$ Department of Pharmacy Practice, Sri Adichunchanagiri College of Pharmacy, Adichunchanagiri University, Bala Gangadharanatha Nagara, \\ Karnataka, India; ${ }^{5}$ Department of Physiotherapy and Rehabilitation Sciences, Jagadguru Sri Shivarathreeshwara, College of Physiotherapy, \\ Rajiv Gandhi University of Health Sciences, Karnataka, India
}

OBJECTIVES: To address and elucidate the impact of pharmacist-led home medicines review (HMR) services on identifying drug-related problems (DRPs) among the elderly population in home care settings.

METHODS: A comprehensive systematic search was performed using electronic scientific databases such as PubMed, Scopus, Embase, and Web of Science for studies published between January 1, 2008 and December 31, 2018, pertaining to HMR services by pharmacists for identifying DRPs.

RESULTS: In total, 4,292 studies were retrieved from the searches, of which 24 were excluded as duplicates. Titles and abstracts were screened for the remaining 4,268 studies, of which 4,239 were excluded due to the extraneous nature of the titles and/or abstracts. Subsequently, 29 full-text articles were assessed, and 19 were removed for lacking the outcome of interest and/or not satisfying the study's inclusion criteria. Finally, 10 studies were included in the review; however, publication bias was not assessed, which is a limitation of this study. In all studies, pharmacists identified a highly significant amount of DRPs through HMR services. The most common types of DRPs were potential drug-drug interactions, serious adverse drug reactions, need for an additional drug, inappropriate medication use, non-adherence, untreated indications, excessive doses, and usage of expired medications.

CONCLUSIONS: HMR is a novel extended role played by pharmacists. The efficiency of such programs in identifying and resolving DRPs could minimize patients' health-related costs and burden, thereby enhancing the quality of life and well-being among the elderly.

KEY WORDS: Pharmacists, Drug-related side effects and adverse reactions, Drug interactions, Aged, Frail elderly

\section{INTRODUCTION}

In countries with numerous and diverse populations, chronic diseases such as hypertension, diabetes, arthritis, and heart disease

\section{Correspondence: Sai Krishna Gudi}

Rady Faculty of Health Sciences, University of Manitoba College of Pharmacy, 750 McDermot Ave W, Winnipeg, MB R3E 0T5, Canada

E-mail:sknanu06@gmail.com

Received: Mar 7, 2019 / Accepted: May 17, 2019 / Published: May 17, 2019

This article is available from: http://e-epih.org/

(C) This is an open-access article distributed under the terms of the Creative Commons Attribution License (http://creativecommons.org/licenses/by/4.0/), which permits unrestricted use, distribution, and reproduction in any medium, provided the original work is properly cited.

(C) 2019, Korean Society of Epidemiology are common, especially among geriatric individuals; as a result, polypharmacy is a frequently occurring phenomenon in the elderly. Polypharmacy may give rise to various drug-related problems (DRPs), such as drug-drug interactions, adverse drug reactions (ADRs), medication errors, and drug-food interactions, which could eventually reduce levels of medication adherence [1]. At times, elderly patients might not take their medications as prescribed, which could evolve into altering the dose, frequency, or terminating the medication itself. The reasons for this may vary from simple logistical misunderstandings of factors such as the appropriate timing and dosage to a deeper misunderstanding of the purpose of a medication. Thus, inappropriate medication use among this vulnerable population is a major health concern [2]. ADRs are a major burden to patients, as shown by the fact that they are considered the fifth most common cause of death 
amongst hospitalized patients, with a notable morbidity rate of $5.6 \%$ in India. Therefore, several studies have been conducted to develop strategies for minimizing and preventing DRPs, including home medicines review (HMR) programs $[3,4]$.

In 2001, the Australian government initiated the first HMR program, defined as a consumer-focused, structured, and collaborative health care service in the community setting to promote better medication adherence [5]. It is a team-based approach that involves a clinician, pharmacist, and consumer to optimize the quality use of medicines and to improve consumers' understanding of their medications. HMR starts with a referral by a clinician, which enables the pharmacist to visit the patient's home in order to review the current medication therapy of that particular patient, to check for potential DRPs, and to resolve them in consultation with the responsible clinician $[1,2]$. The essential goal of the HMR program is to reduce the DRPs that are derived from inappropriate use of medicines, as doing so could enhance patients' medication adherence [6]. In this review, we sought to critically inspect studies of the effects of pharmacist-initiated HMR programs on identifying and mitigating DRPs.

\section{MATERIALS AND METHODS}

\section{Data sources and search strategy}

A comprehensive search was performed of PubMed, Scopus, Embase, and Web of Science for peer-reviewed, full-text articles published in the English language between January 1, 2008 and December 31, 2018. Relevant keywords such as "HMR," "home medicines review," "drug related problems," "pharmacist," and "elderly" were searched in diverse combinations with Medical Subject Headings (MeSH) terms by using Boolean operators to identify all relevant studies. The detailed search strategy interpretation using PubMed was as follows: ("HMR" [All Fields] OR "home medicines review" [All Fields]) AND "drug-related problems" [All Fields] AND "pharmacists" [MeSH Terms] OR "pharmacists" [All Fields] AND ("aged" [MeSH Terms] OR "aged" [All Fields] OR “elderly” [All Fields]) AND (“2008/01/01” [PDAT]: “2018/12/31” [PDAT]). Any further missing publications were searched by checking the references of the included studies. ProQuest, Google Scholar, and Open Grey were searched for the grey literature.

\section{Study selection and data extraction}

Three reviewers (SKG, AK, and MC) independently screened the title and abstract of each article, and the potentially eligible full-texts of relevant abstracts were obtained and screened to identify articles of interest based on the study's inclusion criteria, which were studies (prospective, retrospective, cross-sectional, or randomized) evaluating the impact of pharmacist-led HMR services on identifying DRPs among the elderly population. Articles were excluded if the outcome data were not reported in enough detail, the participants were not elderly, and the studies were conducted elsewhere from home or home care facilities; additionally, duplicate publications, literature reviews, conference abstracts, studies with no pharmacist involvement, and editorials/letters to the editor were excluded. The retrieved studies were imported into the Rayyan software [7] to remove duplicates and to review studies based on the inclusion and exclusion criteria. From each included study, the following data were extracted: author name(s), publication year, country, study design, sample size, mean age of the participants, key findings, and the summary. Any disagreements amongst the researchers regarding the inclusion of the studies were resolved through consensus, and a priori protocol was developed, and can be found in the Supplementary Material 1.

\section{Risk of bias and quality assessment}

The risk of bias and methodological quality of each included study were assessed by 2 independent reviewers (AK and SKG) using the Standard Quality Assessment Criteria for Evaluating Primary Research Papers from a Variety of Fields [8], a 14-item measurement tool used to assess the methodological quality of the studies in a systematic review. Each item/question was scored as 2 (if the response was 'yes'), 1 (if the response was 'partial'), or 0 (if the response was 'no'). Questions that were not applicable to a particular study were marked as ' $\mathrm{n} / \mathrm{a}$ ' and were excluded from the calculation of the summary score, which was calculated for each paper by summing the total score obtained for all items and dividing it by the total possible score. A higher summary score indicated a lower risk of bias and better study quality. Disagreements were resolved by discussions or by a third reviewer.

\section{Outcome assessment}

The outcome of interest of this review was DRPs, which were assessed in terms of their frequency, type, and nature as described in each included study. DRPs were defined as an event or circumstance involving drug therapy that potentially interfered with desired health outcomes.

\section{RESULTS}

Initially, 4,292 studies were retrieved from the search, of which 24 were excluded as duplicates. Titles and abstracts were screened for the remaining 4,268 studies, of which 4,239 were excluded due to the extraneous nature of the titles and/or abstracts. Subsequently, 29 full-text articles were assessed, and 19 were removed for lacking the outcome of interest and/or not satisfying the study's inclusion criteria. Finally, 10 studies were included in the review, as shown in detail in the PRISMA (Preferred Reporting Items for Systematic Reviews and Meta-Analyses) flow-chart in Figure 1.

\section{Characteristics of selected studies}

The characteristics of the 10 included studies are described in Table 1 . The plurality of the studies (4) were conducted in Australia [9-12], and one was conducted in each of the following countries: Sweden [13], India [14], Canada [15], Jordan [16], Germany [17], and Singapore [18]. Most of the studies utilized cross-sectional [13$16]$ and retrospective study designs $[9,11,12,18]$. There was mean- 


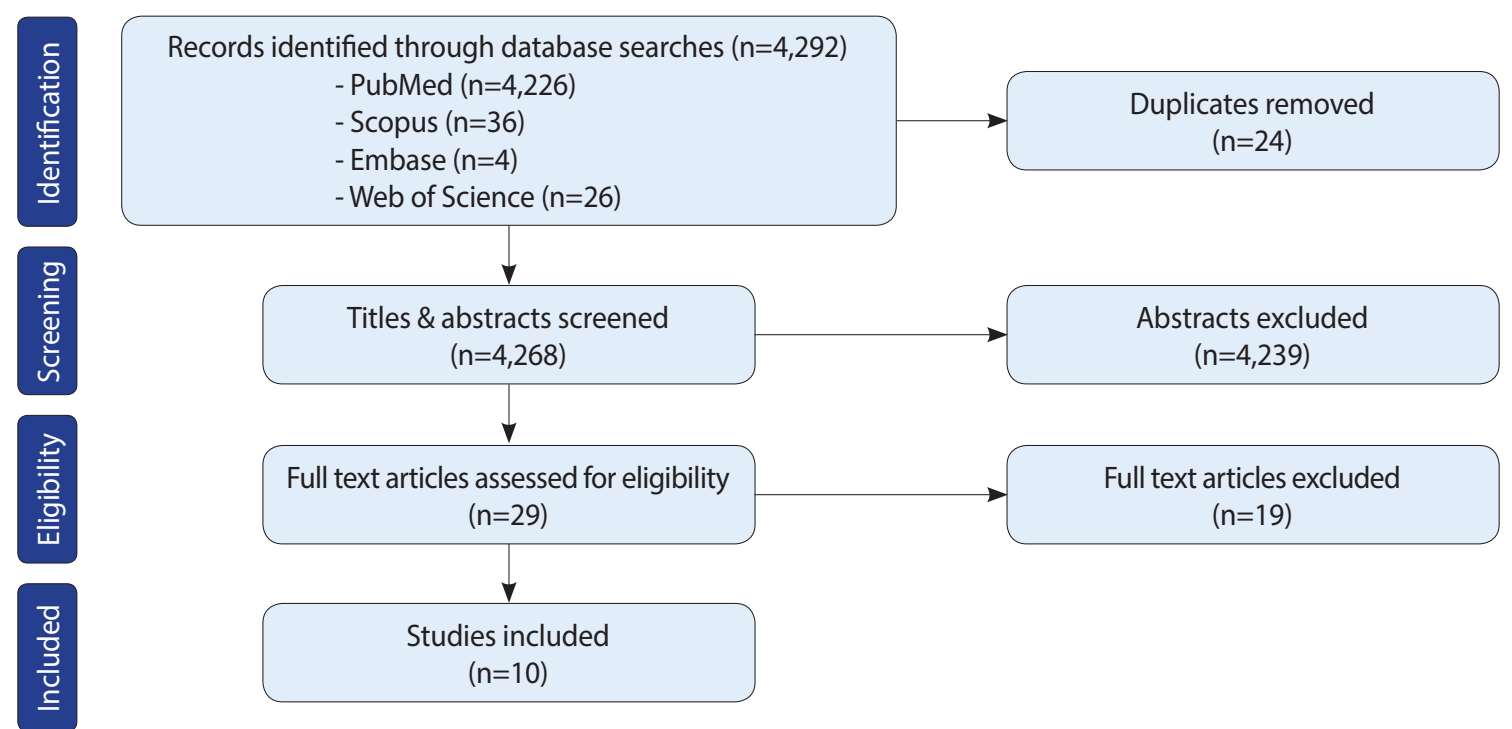

Figure 1. Preferred Reporting Items for System reviews and Meta-Analyses (PRISMA) flow-chart depicting the study selection process.

ingful variation in the sample size across the included studies, ranging from 37 [17] to 1,720 [13]. In most of the studies, the mean age of the population was $\geq 65$ years, except in 2 studies $[14,16]$.

\section{Quality evaluation criteria}

The quality of the studies was assessed using the Standard Quality Assessment Criteria for Evaluating Primary Research Papers from a Variety of Fields, which was developed by Kmet et al. [9]. The quality scores of most studies ranged from $80 \%$ to $100 \%$, although 1 study [12] had the maximum score of $100 \%$ and 1 study [18] had a lower score (77\%). Overall, the quality of the included studies was satisfactory. The quality scores of each study are presented in Table 2 .

\section{DISCUSSION}

HMR programs are emerging as one of the extended roles of community pharmacists in developed countries such as Australia, the USA, Canada, and various European countries $[4,19,20]$. Unfortunately, such programs have not been launched in most developing countries, such as India, for diverse reasons including the reluctance of general practitioners to follow recommendations made by pharmacists, a lack of awareness regarding HMR services among the public, patients' conflicts of interest and privacy issues that affect their willingness to disclose their disease status and medication use, and linguistic and cultural diversity $[5,6]$. However, a few studies have investigated the influence of pharmacist-provided patient counseling services and found that such counseling services led to significant improvements in health outcomes in patients with chronic diseases [21-25]. The professional bodies in Australia have developed guidelines on HMR activities to assist community pharmacists in exercising professional judg- ment in individual health care circumstances and to promote the quality use of medicines to achieve better patient care. Diverse international studies of HMR services have reflected on optimizing medication use, minimizing DRPs, and improvising better health care outcomes in patients with chronic diseases and polypharmacy [26].

In addition to improving health care outcomes by fostering an understanding of one's medicines and the ability to manage those medicines appropriately, HMR services also provide recommendations for general practitioners on any potential DRPs that may affect patient safety [27]. A study conducted by Dhillon et al. [6] on general practitioners' perceptions of HMR programs confirmed that HMR improved general practitioners' knowledge of the medicines that their patients were taking. A study conducted by Turner et al. [26] in Australia assessed the benefits of HMR and stated that pharmacists identified expired and unwanted over-the-counter medications with the patients during the comprehensive medication review [26]. Another study conducted by Gilbert et al. [3] to assess the usefulness of an HMR collaborative service that included 1,000 patients with 129 general practitioners and 63 pharmacists identified that a significant number $(2,900)$ of DRPs were identified, of which $17 \%$ were wrong medication selection and $20 \%$ were poor medication adherence due to an inadequate knowledge of the drug on the part of consumers; in that study, the collaborative efforts of general practitioners and pharmacists helped to resolve $85 \%$ of the DRPs [3].

Besides identifying and resolving DRPs, HMR services provided by pharmacists could significantly decrease the rate of hospital readmission and its associated healthcare expenditures [18]. However, in a systematic review and meta-analysis conducted by Holland et al. [28], it was inferred that pharmacist-led medication review could reduce the number of drugs prescribed, and may im- 


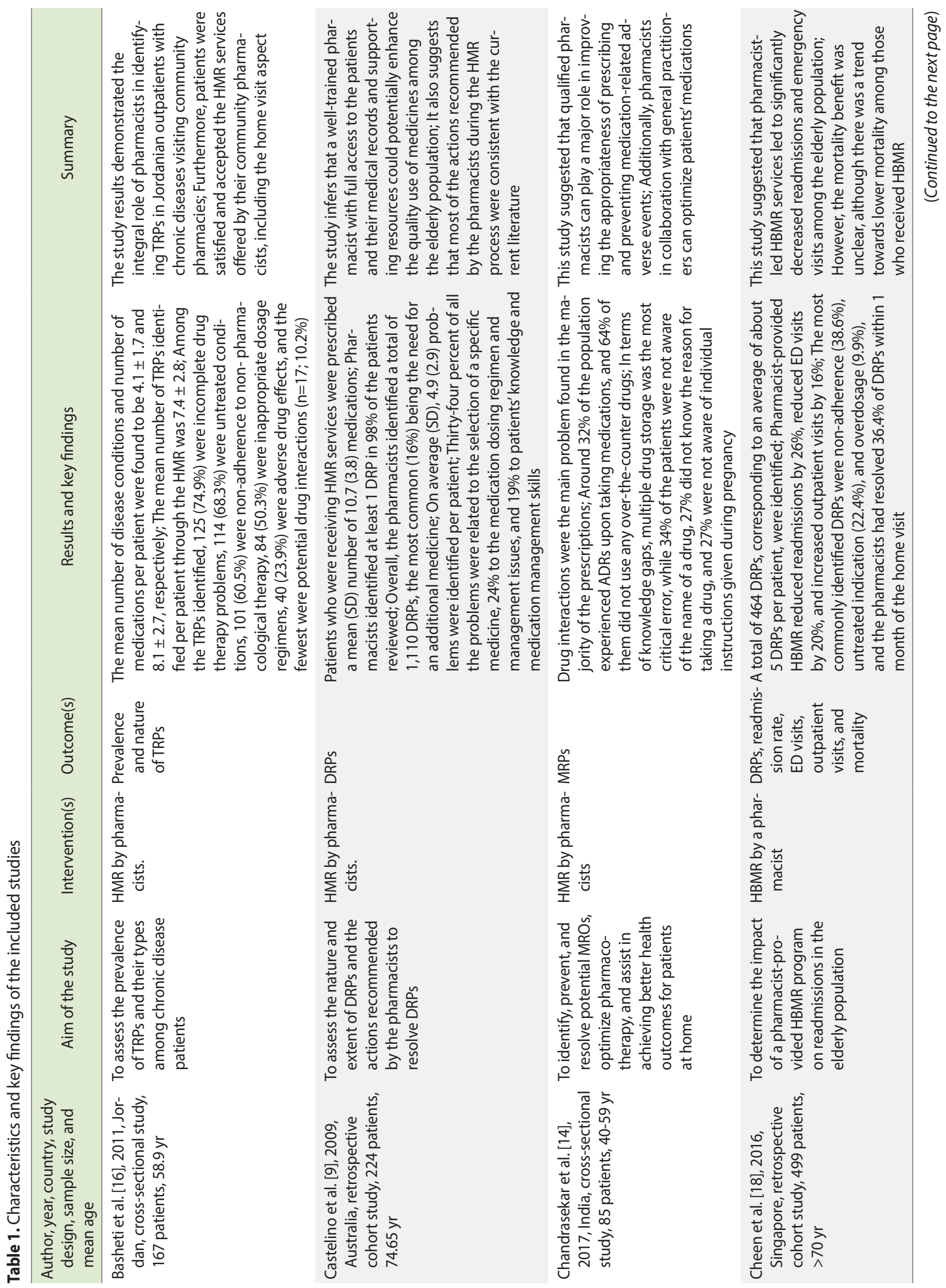




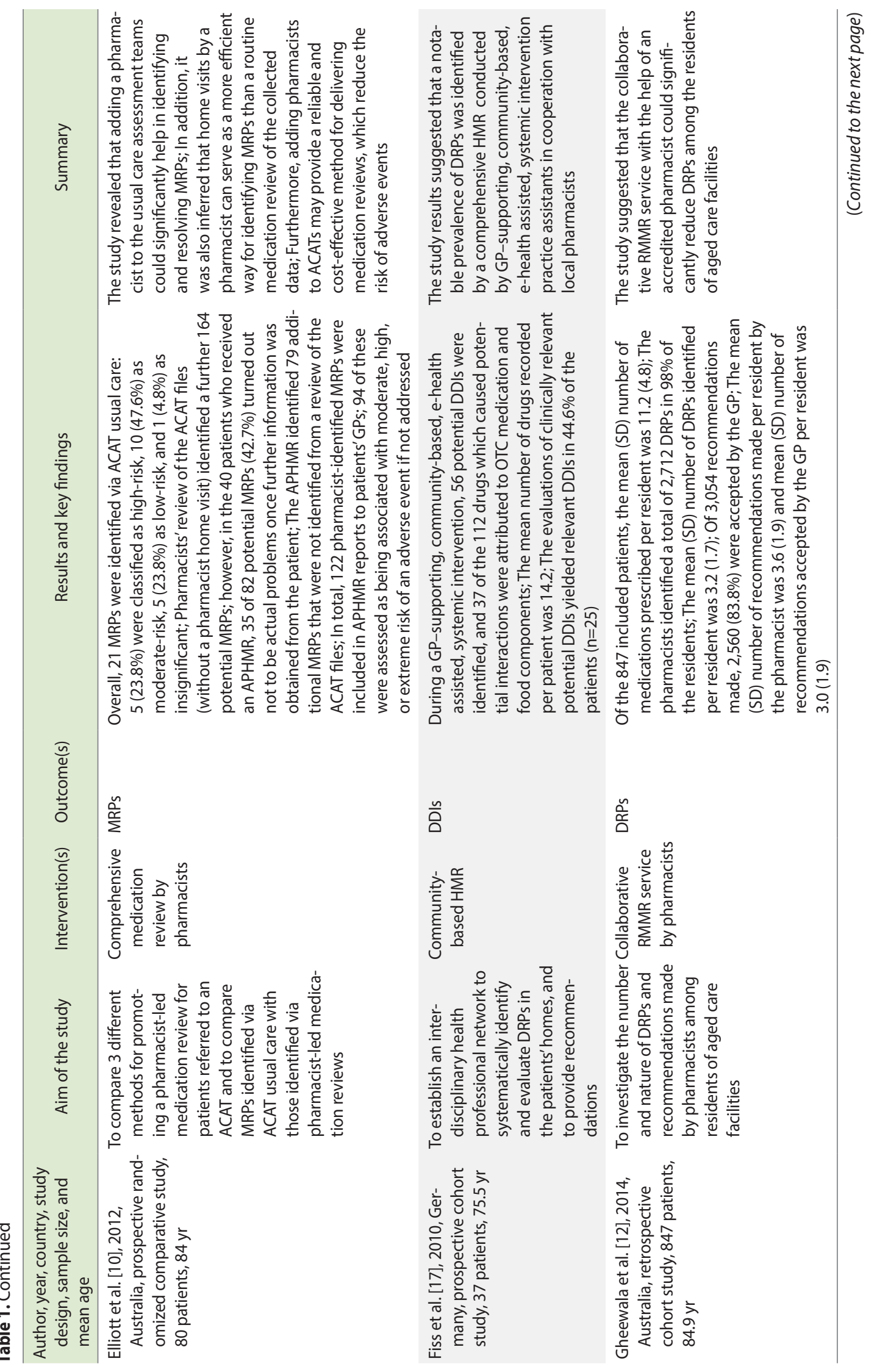




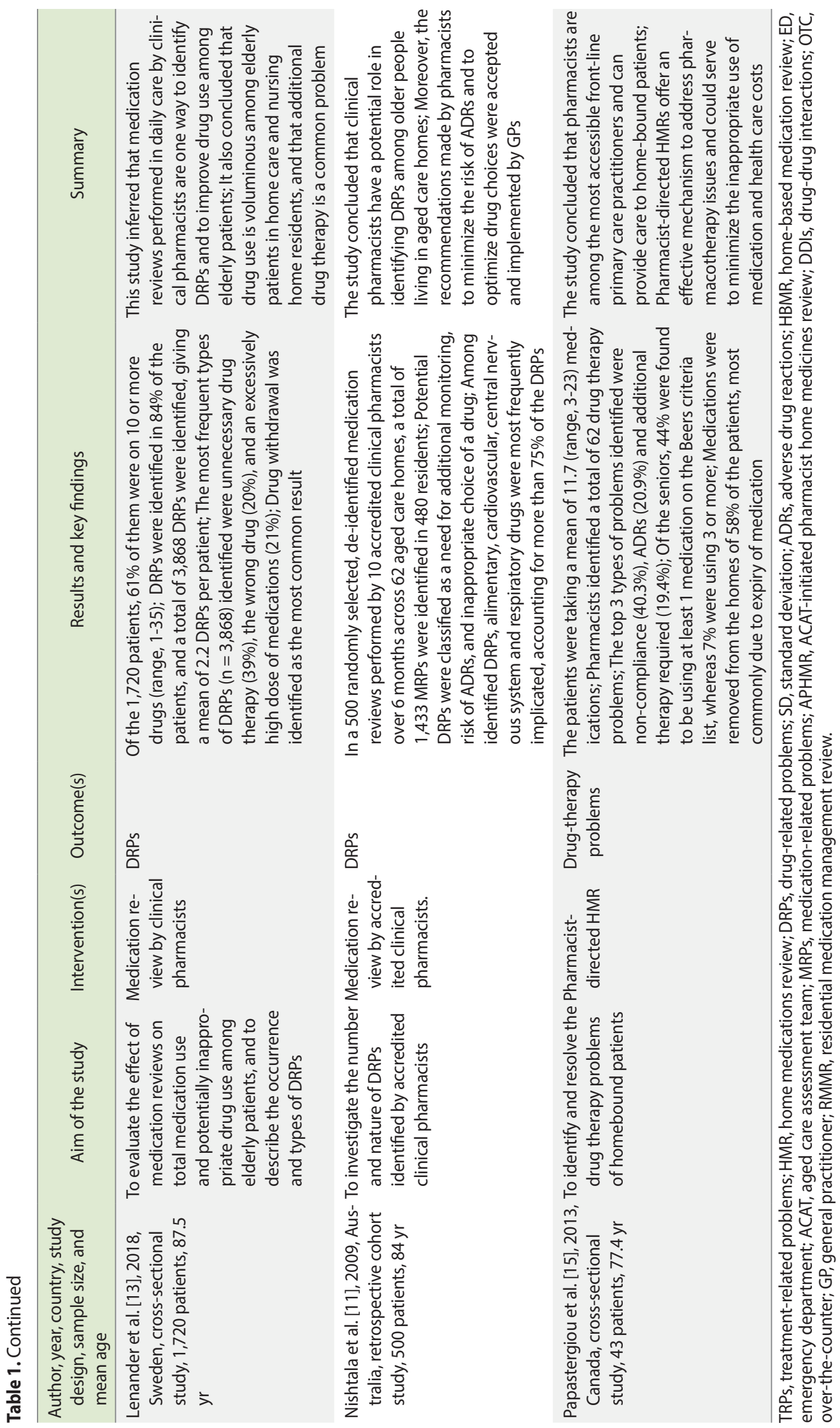


Table 2. Quality evaluation of the included studies

\begin{tabular}{|c|c|c|c|c|c|c|c|c|c|c|}
\hline \multirow{2}{*}{ Criteria } & \multicolumn{10}{|c|}{ Study } \\
\hline & [9] & {$[10]$} & {$[17]$} & [18] & [11] & [13] & {$[12]$} & {$[14]$} & {$[15]$} & [16] \\
\hline Question/objective sufficiently described? & 2 & 2 & 2 & 2 & 2 & 2 & 2 & 2 & 2 & 2 \\
\hline Study design evident and appropriate? & 2 & 2 & 2 & 2 & 2 & 2 & 2 & 2 & 2 & 2 \\
\hline $\begin{array}{l}\text { Method of subject/comparison group selection or source of infor- } \\
\text { mation/input variables described and appropriate? }\end{array}$ & 2 & 2 & 2 & 2 & 2 & 2 & 2 & 1 & 2 & 2 \\
\hline $\begin{array}{l}\text { Subject (and comparison group, if applicable) characteristics suf- } \\
\text { ficiently described? }\end{array}$ & 2 & 2 & 2 & 2 & 2 & 2 & 2 & 1 & 2 & 2 \\
\hline $\begin{array}{l}\text { If interventional and random allocation was possible, was it de- } \\
\text { scribed? }\end{array}$ & $\mathrm{N} / \mathrm{A}$ & 2 & $\mathrm{~N} / \mathrm{A}$ & $\mathrm{N} / \mathrm{A}$ & $\mathrm{N} / \mathrm{A}$ & $\mathrm{N} / \mathrm{A}$ & $\mathrm{N} / \mathrm{A}$ & $\mathrm{N} / \mathrm{A}$ & N/A & $\mathrm{N} / \mathrm{A}$ \\
\hline $\begin{array}{l}\text { If interventional and blinding of investigators was possible, was it } \\
\text { reported? }\end{array}$ & $\mathrm{N} / \mathrm{A}$ & 0 & $\mathrm{~N} / \mathrm{A}$ & $\mathrm{N} / \mathrm{A}$ & $\mathrm{N} / \mathrm{A}$ & $\mathrm{N} / \mathrm{A}$ & $\mathrm{N} / \mathrm{A}$ & $\mathrm{N} / \mathrm{A}$ & N/A & $\mathrm{N} / \mathrm{A}$ \\
\hline $\begin{array}{l}\text { If interventional and blinding of subjects was possible, was it } \\
\text { reported? }\end{array}$ & $\mathrm{N} / \mathrm{A}$ & 2 & $\mathrm{~N} / \mathrm{A}$ & $\mathrm{N} / \mathrm{A}$ & $\mathrm{N} / \mathrm{A}$ & $\mathrm{N} / \mathrm{A}$ & $\mathrm{N} / \mathrm{A}$ & $\mathrm{N} / \mathrm{A}$ & N/A & $\mathrm{N} / \mathrm{A}$ \\
\hline $\begin{array}{l}\text { Outcome and (if applicable) exposure measure(s) well defined and } \\
\text { robust to measurement / misclassification bias? Means of assess- } \\
\text { ment reported? }\end{array}$ & 2 & 2 & 1 & 2 & 2 & 2 & 2 & 2 & 2 & 2 \\
\hline Sample size appropriate? & 2 & 2 & 1 & 2 & 2 & 2 & 2 & 2 & 1 & 2 \\
\hline Analytic methods described/justified and appropriate? & 2 & 2 & 2 & 2 & 2 & 2 & 2 & 2 & 1 & 2 \\
\hline Is some estimate of variance is reported for the main results? & 0 & 2 & 0 & 2 & 2 & 0 & 0 & 0 & 0 & 0 \\
\hline Controlled for confounding? & $\mathrm{N} / \mathrm{A}$ & 0 & 1 & 1 & $\mathrm{~N} / \mathrm{A}$ & $\mathrm{N} / \mathrm{A}$ & $\mathrm{N} / \mathrm{A}$ & $\mathrm{N} / \mathrm{A}$ & N/A & $\mathrm{N} / \mathrm{A}$ \\
\hline Results reported in sufficient detail? & 2 & 2 & 2 & 2 & 2 & 2 & 2 & 2 & 2 & 2 \\
\hline Conclusions supported by the results? & 2 & 2 & 2 & 2 & 2 & 2 & 2 & 2 & 2 & 2 \\
\hline Maximum points & 20 & 28 & 22 & 22 & 20 & 20 & 20 & 20 & 20 & 20 \\
\hline Total points & 18 & 24 & 17 & 21 & 20 & 18 & 18 & 16 & 16 & 18 \\
\hline Summary score (\%) & 90 & 86 & 77 & 95 & 100 & 90 & 90 & 80 & 80 & 90 \\
\hline
\end{tabular}

0 , if the response is 'no'; 1 , if the response is 'partial'; 2 , if the response is 'yes'; N/A, not applicable.

prove patients' drug-related knowledge and adherence behavior, but has no effect on mortality and morbidity. Furthermore, another study conducted by Pacini et al. [29] reported that HMR services provided by pharmacists did not reduce hospital admissions; instead, they observed only a minimal benefit in patients' health-related quality of life that was not statistically significant.

In a quantitative survey of the views of HMR recipients conducted by Carter et al. [30], respondents reported the highest level of agreement that HMR would be of help in understanding more about their medications and rated the interpersonal skills of the visiting pharmacist as extremely high. In another study that attempted to assess the willingness of caregivers to assist their carerecipients with $\mathrm{HMR}$, it was concluded that building expectations of HMR as an information resource among informal caregivers would likely increase the overall consumer demand for this service, which may ease the stress and burden of caregiving [31]. An Australian survey of consumers' perspectives on HMR reported that those with the greatest need of the services were the least likely to receive HMR, and that the service recipients were wellsatisfied with the HMR and recognized the benefits of the process [27]. However, patient involvement and cooperation are essential for them to receive a benefit from HMR services. In this review, we have sought to summarize and encapsulate the diverse findings of studies addressing the role of pharmacists in offering
HMR services in community home care settings. Nonetheless, this study has certain limitations, including the inability to evaluate the results through a meta-analysis due to the small number of studies and the diverse outcome measures assessed in those studies, as well as the exclusion of studies without full-text access [32-35]. Furthermore, not appraising the risk of publication bias is a drawback of this study.

\section{CONCLUSION}

If utilized appropriately, HMR services provided by pharmacists could assist patients in minimizing and/or averting DRPs to a significant extent, especially among the elderly. To prevent medication accidents and to improve adherence among patients, it is necessary to implement HMR services, and necessary measures should be taken by health regulatory bodies to increase awareness of HMR and to make use of existing HMR tools among the public. However, further robust research should be conducted to evaluate the effects of HMR programs on reducing hospital admissions and emergency visits.

\section{SUPPLEMENTARY MATERIALS}

Supplementary material is available at http://www.e-epih.org/. 


\section{CONFLICT OF INTEREST}

The authors have no conflicts of interest to declare for this study.

\section{ACKNOWLEDGEMENTS}

None.

\section{AUTHOR CONTRIBUTIONS}

Conceptualization: SKG, KKT. Data curation: AK, MC, MR. Formal analysis: SKG, KKT, AK. Funding acquisition: None. Methodology: SKG, AK. Project administration: SKG, AK, KKT. Visualization: MC, MR. Writing - original draft: SKG, AK, KKT. Writing - review \& editing: SKG.

\section{ORCID}

Sai Krishna Gudi: https://orcid.org/0000-0001-9576-9207; Ananth Kashyap: https://orcid.org/0000-0003-0611-4191; Manik Chhabra: https://orcid.org/0000-0002-8924-8242; Muhammed Rashid: https://orcid.org/0000-0002-6390-7764

\section{REFERENCES}

1. Hajjar ER, Cafiero AC, Hanlon JT. Polypharmacy in elderly patients. Am J Geriatr Pharmacother 2007;5:345-351.

2. Castelino RL, Bajorek BV, Chen TF. Retrospective evaluation of home medicines review by pharmacists in older Australian patients using the medication appropriateness index. Ann Pharmacother 2010;44:1922-1929.

3. Gilbert AL, Roughead EE, Beilby J, Mott K, Barratt JD. Collaborative medication management services: improving patient care. Med J Aust 2002;177:189-192.

4. Willis JS, Hoy RH, Jenkins WD. In-home medication reviews: a novel approach to improving patient care through coordination of care. J Community Health 2011;36:1027-1031.

5. Ahn J, Park JE, Anthony C, Burke M. Understanding, benefits and difficulties of home medicines review-patients' perspectives. Aust Fam Physician 2015;44:249-253.

6. Dhillon AK, Hattingh HL, Stafford A, Hoti K. General practitioners' perceptions on home medicines reviews: a qualitative analysis. BMC Fam Pract 2015;16:16.

7. Ouzzani M, Hammady H, Fedorowicz Z, Elmagarmid A. Rayyan-a web and mobile app for systematic reviews. Syst Rev 2016;5: 210.

8. Kmet LM, Lee RC, Cook LS. Standard quality assessment criteria for evaluating primary research papers from a variety of fields. Edmonton: Alberta Heritage Foundation for Medical Research; 2004, p. 1-22.

9. Castelino RL, Bajorek BV, Chen TF. Are interventions recommended by pharmacists during home medicines review evi- dence-based? J Eval Clin Pact 2011;17:104-110.

10. Elliott RA, Martinac G, Campbell S, Thorn J, Woodward MC. Pharmacist-led medication review to identify medication-related problems in older people referred to an Aged Care Assessment Team: a randomized comparative study. Drugs Aging 2012;29:593605.

11. Nishtala PS, McLachlan AJ, Bell JS, Chen TF. A retrospective study of drug-related problems in Australian aged care homes: medication reviews involving pharmacists and general practitioners. J Eval Clin Pract 2011;17:97-103.

12. Gheewala PA, Peterson GM, Curtain CM, Nishtala PS, Hannan PJ, Castelino RL. Impact of the pharmacist medication review services on drug-related problems and potentially inappropriate prescribing of renally cleared medications in residents of aged care facilities. Drugs Aging 2014;31:825-835.

13. Lenander C, Bondesson $\AA$, Viberg N, Beckman A, Midlöv P. Effects of medication reviews on use of potentially inappropriate medications in elderly patients; a cross-sectional study in Swedish primary care. BMC Health Serv Res 2018;18:616.

14. Chandrasekhar D, Joseph E, Ghaffoor FA, Thomas HM. Role of pharmacist led home medication review in community setting and the preparation of medication list. Clin Epidemiol Glob Health 2019;7:66-70.

15. Papastergiou J, Zervas J, Li W, Rajan A. Home medication reviews by community pharmacists: reaching out to homebound patients. Can Pharm J 2013;146;139-142.

16. Basheti IA, Qunaibi EA, Bulatova NR, Samara S, AbuRuz S. Treatment related problems for outpatients with chronic diseases in Jordan: the value of home medication reviews. Int J Clin Pharm 2013;35:92-100.

17. Fiss T, Ritter CA, Alte D, van den Berg N, Hoffmann W. Detection of drug related problems in an interdisciplinary health care model for rural areas in Germany. Pharm World Sci 2010;32:566574.

18. Cheen MH, Goon CP, Ong WC, Lim PS, Wan CN, Leong MY, et al. Evaluation of a care transition program with pharmacist-provided home-based medication review for elderly Singaporeans at high risk of readmissions. Int J Qual Health Care 2017;29:200-205.

19. Quirke J, Wheatland B, Gilles M, Howden A, Larson A. Home medicines reviews - do they change prescribing and patient/pharmacist acceptance? Aust Fam Physician 2006;35:266-267.

20. Elina AN, Suraya MC, Ball PA. The impact of home medication review in patients with type 2 diabetes mellitus living in rural areas of Kuantan, Malaysia. Value Health 2014;17:A127.

21. Srinivas B, Shivram G, Swapnali M, Pratibha C, Sagar B, Kailash V. Betterment of patient to get optimal health outcomes through home medicines review (HMR). Int J Pharm Res Allied Sci 2014; 3:10-16.

22. Mishra A, Krishna GS, Alla S, Kurian TD, Kurian J, Ramesh M, et al. Impact of pharmacist-psychiatrist collaborative patient education on medication adherence and quality of life (QOL) of Bipolar Affective Disorder (BPAD) patients. Front Pharmacol 2017;8:722.

23. Mishra A, Krishna GS, Sravani A, Kurian TD, Kurian J, Ramesh M, 
et al. Impact of pharmacist-led collaborative patient education on medication adherence and quality of life of schizophrenia patients in a tertiary care setting. Bull Fac Pharm Cairo Univ 2017;55:345349.

24. Gudi SK. Assessment of knowledge, attitude and perceptions of HIV/AIDS among secondary school students in Guntur district of south India: a cross-sectional survey. Int J Sci Rep 2018;4:87-92.

25. Gudi SK, Chhabra M, Rashid M. Assessment of the impact of pharmacist-led face-to-face counselling on HIV/AIDS among school \& college going students, and infected patients in south India. Clin Epidemiol Glob Health 2019. doi: https://doi.org/10.1016/ j.cegh.2019.01.006.

26. Turner JP, Bell JS. Implementation of pharmacist-led medication reviews in general practice. Int J Clin Pharm 2013;35:3-4.

27. White L, Klinner C, Carter S. Consumer perspectives of the Australian Home Medicines Review Program: benefits and barriers. Res Social Adm Pharm 2012;8:4-16.

28. Holland R, Desborough J, Goodyer L, Hall S, Wright D, Loke YK. Does pharmacist-led medication review help to reduce hospital admissions and deaths in older people? A systematic review and meta-analysis. Br J Clin Pharmacol 2008;65:303-316.

29. Pacini M, Smith RD, Wilson EC, Holland R. Home-based medi- cation review in older people: is it cost effective? Pharmacoeconomics 2007;25:171-180.

30. Carter SR, Chen TF, White L. Home medicines reviews: a quantitative study of the views of recipients and eligible non-recipients. Int J Pharm Pract 2012;20:209-217.

31. Carter SR, Moles R, White L, Chen TF. The willingness of informal caregivers to assist their care-recipient to use home medicines review. Health Expect 2016;19:527-542.

32. Steele KM, Ruisinger JF, Bates J, Prohaska ES, Melton BL, Hipp S. Home-based comprehensive medication reviews: pharmacist's impact on drug therapy problems in geriatric patients. Consult Pharm 2016;31:598-605.

33. Alderman CP, Kong L, Kildea L. Medication-related problems identified in home medicines reviews conducted in an Australian rural setting. Consult Pharm 2013;28:432-442.

34. Vink J, Morton D, Ferreri S. Pharmacist identification of medication-related problems in the home care setting. Consult Pharm 2011;26:477-484.

35. Stuijt CC, Franssen EJ, Egberts AC, Hudson SA. Appropriateness of prescribing among elderly patients in a Dutch residential home: observational study of outcomes after a pharmacist-led medication review. Drugs Aging 2008;25:947-954. 